\begin{tabular}{|c|c|c|}
\hline \multirow{3}{*}{$\begin{array}{r}\text { Case Reports in } \\
\text { Gastroenterology }\end{array}$} & \multirow{2}{*}{\multicolumn{2}{|c|}{ Case Rep Gastroenterol 2014;8:51-55 }} \\
\hline & & \\
\hline & $\begin{array}{l}\text { DOI: 10.1159/000358552 } \\
\text { Published online: January 25, } 2014\end{array}$ & $\begin{array}{l}\text { (c) } 2014 \text { S. Karger AG, Basel } \\
\text { 1662-0631/14/0081-0051 } \$ 39.50 / 0 \\
\text { www.karger.com/crg }\end{array}$ \\
\hline & \multicolumn{2}{|c|}{$\begin{array}{l}\text { This is an Open Access article licensed under the terms of the Creative Commons } \\
\text { Attribution-NonCommercial } 3.0 \text { Unported license (CC BY-NC) (www.karger.com/OA } \\
\text { license), applicable to the online version of the article only. Distribution permitted for non } \\
\text { commercial purposes only. }\end{array}$} \\
\hline
\end{tabular}

\title{
Gastrointestinal Endometriosis Causing Subacute Intestinal Obstruction with Gradual Development of Weight Loss and Misdiagnosed as Irritable Bowel Syndrome
}

\author{
Amir Soumekh Jerry Nagler \\ Division of Gastroenterology and Hepatology, Department of Medicine, Weill Cornell \\ Medical College, New York, N.Y., USA
}

\section{Key Words}

Irritable bowel syndrome · Endometriosis · Intestinal obstruction · Functional bowel disorders

\begin{abstract}
Both endometriosis and irritable bowel syndrome (IBS) are commonly found in young women and the diagnosis of either is challenging. Alarm symptoms can exclude the diagnosis of IBS, but their onset may be insidious and often no evidence of organic disease may be found. We present a patient with a 4-year history of presumed IBS, absent gynecological symptoms, negative gastrointestinal as well as gynecological testing who developed the only alarm symptom of weight loss and was eventually found to have endometriosis of the small intestine. This case illustrates the need for constant vigilance in patients with IBS.
\end{abstract}

(C) 2014 S. Karger AG, Basel

\section{Introduction}

Irritable bowel syndrome (IBS) affects 5-20\% of individuals worldwide, most often women $<50$ years of age [1]. Similarly, endometriosis is very common in this same population, affecting up to $15 \%$ of menstruating women [2]. Gastrointestinal involvement in endometriosis occurs in only $3-7 \%$ of cases, mostly in the rectosigmoid region and only very rarely in the small intestine [3]. Typically endometriosis patients complain of dysmenorrhea, pelvic pain, ovulation pain, dyspareunia and dyschezia, while patients with IBS complain of 
Soumekh et al.: Gastrointestinal Endometriosis Causing Subacute Intestinal

Obstruction with Gradual Development of Weight Loss and Misdiagnosed as IBS

abdominal pain associated with a change in the frequency or consistency of stools and abdominal bloating [4]. Alarm symptoms, which might indicate another diagnosis but are non-specific, include: fever, weight loss, blood in the stools, anemia, abnormal physical findings, abnormal blood tests, and a family history of cancer, inflammatory bowel disease or celiac disease [5]. We present the case of a young woman with a 4-year history of IBS on the basis of abdominal pain associated with constipation, flatus, belching and bloating without gynecological symptoms, and who was eventually discovered to have endometriosis following surgery for a distal ileal stricture. Her symptoms totally resolved postoperatively. She had undergone prior extensive unremarkable gastrointestinal and gynecological diagnostic testing. Her only distinguishing feature was the alarm symptom of weight loss.

\section{Case Report}

A 44-year-old woman noted the onset of upper and lower abdominal pain associated with constipation approximately 4 years ago. Her symptoms were worse following meals, especially if they included fried foods, fatty foods, coffee or carbonated beverages. Episodes occurred every 2-3 days with occasional emesis but no history of hematemesis, melena or hematochezia. Her appetite remained good, but she noted a weight loss of $25 \mathrm{lb}$ over the past year. There was no history of alcohol, coffee, aspirin or non-steroidal inflammatory medication abuse. She denied dyspareunia or painful menstrual periods. Her only operations were a cesarean section in 2003 and cholecystectomy in 2004.

On physical examination she appeared to be well-developed, well-nourished and in no acute distress. Her abdomen was non-tender and without palpable masses, organomegaly or distention. Right upper quadrant laparoscopy and suprapubic surgical scars were noted. Rectal examination demonstrated no masses or tenderness, with brown guaiac negative stool present in the rectal ampulla. Papanicolaou smear and gynecological examination performed by her gynecologist 1 month previously were normal. Her diagnostic work-up included normal complete blood count, liver and kidney function tests, thyroid function and C-reactive protein. Upper endoscopy and colonoscopy examinations were normal except for internal hemorrhoids. Abdominal and pelvic sonography were normal except for evidence of a prior cholecystectomy, mild fatty liver and a simple right ovarian cyst. A lactose tolerance test was positive.

On the basis of her symptoms and negative diagnostic work-up, the diagnoses of IBS, gastroesophageal reflux and lactose intolerance were made. Treatment with antacids and an anti-cholinergic did not provide relief. Due to her recurrent symptoms, a Computed tomography enterography examination was performed to evaluate the small intestine. This revealed a partial small bowel obstruction located approximately $5 \mathrm{~cm}$ proximal to the ileocecal valve (fig. 1). Subsequent surgical resection and histology identified the cause of the partial obstruction to be endometriosis with focal submucosal hemorrhage and serosal scarring (fig. 2, fig. 3). The patient became totally asymptomatic postoperatively.

\section{Discussion}

Endometriosis most commonly presents with gynecological symptoms of intermenstrual bleeding, premenstrual exacerbation of pain and forniceal tenderness, while IBS symptoms include more upper abdominal pain, colicky pain and exacerbation of pain by food or stress, as seen in this patient [6]. Endometriosis involving the intestinal tract is rare and 
Soumekh et al.: Gastrointestinal Endometriosis Causing Subacute Intestinal

Obstruction with Gradual Development of Weight Loss and Misdiagnosed as IBS

often asymptomatic. However, when symptoms do occur they can mimic those of IBS [7]. Our patient met the Rome III diagnostic criteria for IBS with onset greater than 6 months of abdominal discomfort for at least 3 days per month over the past 3 months plus a change in stool frequency (constipation) and appearance (small hard stools), except for the alarm symptom of weight loss [8]. Other possible alarm symptoms include older age at symptom onset, gastrointestinal bleeding, dysphagia, anemia, fever and family history of cancer. Even with the presence of an alarm symptom, most patients are clinically considered to have IBS if symptom-guided testing is negative, and our patient underwent upper endoscopy, colonoscopy, abdominal sonography, pelvic sonography and gynecological examinations, all of which failed to reveal any other diagnoses. A large chart review of 1,434 patients with a clinical diagnosis of IBS revealed alarm features in $84 \%$, yet only $7-9 \%$ of them were found to have organic disease [9]. In a study of 200 consecutive patients with a clinical diagnosis of an IBS who were prospectively evaluated, $70 \%$ had alarm symptoms, but significant organic disease could only be found in $5 \%$, with another $20 \%$ having bacterial overgrowth, lactose or fructose malabsorption [10]. An analysis of multiple studies involving diagnostic testing in patients with a clinical diagnosis the IBS concluded that the probability of finding organic disease was $<1 \%$; only celiac disease was found to be markedly higher than in the general population [11].

The significance of weight loss, defined as at least 5\% decrease in body weight over 6-12 months as seen in our patient, is uncertain. One review of published studies involving 881 patients found that in older patients (ages 59-72) the three most common causes of unexplained weight loss were malignancy, gastrointestinal disorders and psychiatric problems, yet despite extensive evaluation and prolonged follow-up, no diagnosis could be made in $5-36 \%$ of patients [12]. Another review on the evaluation of weight loss in adults of all ages found that approximately $25 \%$ of patients will not have any diagnosis after testing and follow-up for at least 6 months, and of the remaining 75\% approximately one third will have a malignancy, one third hyperthyroidism, diabetes, peptic ulcer disease or cholelithiasis, and one third will have a psychiatric disorder [13]. In a prospective study of 101 patients with unexplained weight loss presenting to a general internal medicine clinic, no etiology could be found in $28 \%$ after 9 months, and additionally $94 \%$ of patients with no baseline abnormality on standard laboratory tests, chest X-ray and abdominal sonography were not found to have an organic disease as the cause [14].

In conclusion, both IBS and endometriosis are very common among young women of child-bearing age. Unfortunately there is currently no non-invasive test to definitively diagnose either condition. Endometriosis can often be diagnosed only by laparoscopic examination of the abdomen and pelvis, often leading to a delay in diagnosis. Furthermore, it only very rarely affects the intestines [15]. IBS is a clinical diagnosis based upon symptomatic criteria. Alarm symptoms are used to cull out patients with other organic diseases, but are often not sufficiently reliable. Furthermore weight loss, which was the only alarm symptom present in our patient, can be non-specific in many cases. Yet, as our patient illustrates, the presence of any alarm symptom in a young woman considered to have IBS should lead to close continued clinical follow-up and constant vigilance for other possible unusual causes of the presenting symptoms, including endometriosis.

\section{Disclosure Statement}

The authors have no conflicts of interest to disclose. 


\begin{tabular}{l|l}
\hline Case Rep Gastroenterol 2014;8:51-55 \\
\hline DOI: 10.1159/000358552 & $\begin{array}{l}\text { C 2014 S. Karger AG, Basel } \\
\text { www.karger.com/crg }\end{array}$ \\
\hline
\end{tabular}

Soumekh et al.: Gastrointestinal Endometriosis Causing Subacute Intestinal

Obstruction with Gradual Development of Weight Loss and Misdiagnosed as IBS

\section{References}

1 El-Salhy M: Irritable bowel syndrome: diagnosis and pathogenesis. World J Gastroenterol 2012;18:51515163.

-2 Karaman K, Pala EE, Bayol U, Akman O, Olmez M, Unluoglu S, Ozturk S: Endometriosis of the terminal ileum: a diagnostic dilemma. Case Rep Pathol 2012;2012:742035.

-3 De Ceglie A, Bilardi C, Blanchi S, Picasso M, Di Muzio M, Trimarchi A, Conio M: Acute small bowel obstruction caused by endometriosis: a case report and review of the literature. World J Gastroenterol 2008;14:34303434.

-4 Slesser AAP, Sultan S, Kubba F, Sellu DP: Acute small bowel obstruction secondary to intestinal endometriosis, an elusive condition: a case report. World J Emerg Surg 2010;5:27.

-5 American Gastroenterology Association: American Gastroenterological Association medical position statement: irritable bowel syndrome. Gastroenterology 2002;123:2105-2107.

-6 Lea R, Bancroft K, Whorwell PJ: Irritable bowel syndrome, chronic pelvic inflammatory disease and endometriosis: a comparison of symptomatology. Eur J Gastroenterol Hepatol 2004;16:1269-1272.

7 Skoog SM, Foxx-Orenstein AE, Levy MJ, Rajan E, Session DR: Intestinal endometriosis: the great masquerader. Curr Gastroenterol Rep 2004;6:405-409.

-8 Henderson PK, Di Palma JA: Diagnosing irritable bowel syndrome: a changing clinical paradigm. South Med J 2011;104:195-199.

-9 Whitehead WE, Palsson OS, Feld AD, Levy RL, Von Korff M, Turner MJ, Drossman DA: Utility of red flag symptom exclusions in the diagnosis of irritable bowel syndrome. Aliment Pharmacol Ther 2006;24:137146.

10 Black TP, Manolakis CS, Di Palma JA: 'Red flag' evaluation yield in irritable bowel syndrome. J Gastrointestin Liver Dis 2012;21:153-156.

11 Cash BD, Schoenfeld P, Chey WD: The utility of diagnostic tests in irritable bowel syndrome patients: a systematic review. Am J Gastroenterol 2002;97:2812-2819.

-12 Vanderschueren S, Geens E, Knockaert D, Bobbaers H: The diagnostic spectrum of unintentional weight loss. Eur J Intern Med 2005;16:160-164.

13 Bianchi AS, Toy EC, Baker B II: The evaluation of involuntary weight loss. Prim Care Update Ob Gyns 1998;5: 263-267.

14 Metalidis C, Knockaert DC, Bobbaers H, Vanderschueren S: Involuntary weight loss. Does a negative baseline evaluation provide adequate reassurance? Eur J Intern Med 2008;19:345-349.

15 Khwaja SA, Zakaria R, Carneiro HA, Khwaja HA: Endometriosis: a rare cause of small bowel obstruction. BMJ Case Rep DOI: 10.1136/bcr.03.2012.5988.

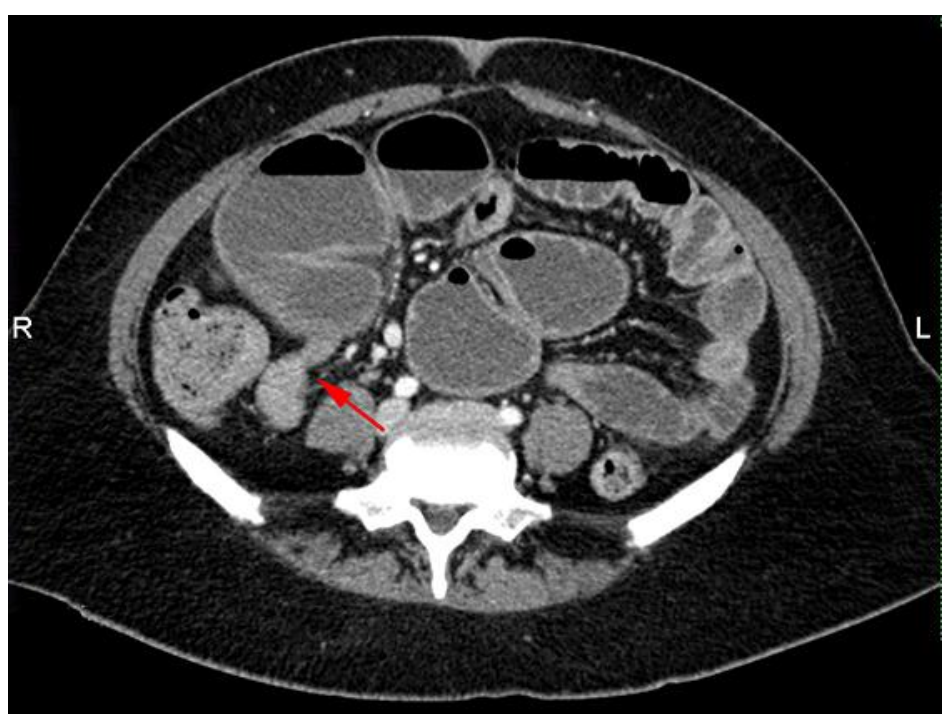

Fig. 1. Computed tomography enterography revealed a partial small bowel obstruction located approximately $5 \mathrm{~cm}$ proximal to the ileocecal valve (red arrow). 


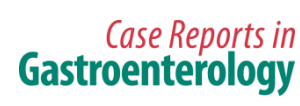

\begin{tabular}{l|l}
\hline \multicolumn{2}{l}{ Case Rep Gastroenterol 2014;8:51-55 } \\
\hline DOI: 10.1159/000358552 & $\begin{array}{l}\text { C 2014 S. Karger AG, Basel } \\
\text { www.karger.com/crg }\end{array}$ \\
\hline
\end{tabular}

Soumekh et al.: Gastrointestinal Endometriosis Causing Subacute Intestinal Obstruction with Gradual Development of Weight Loss and Misdiagnosed as IBS

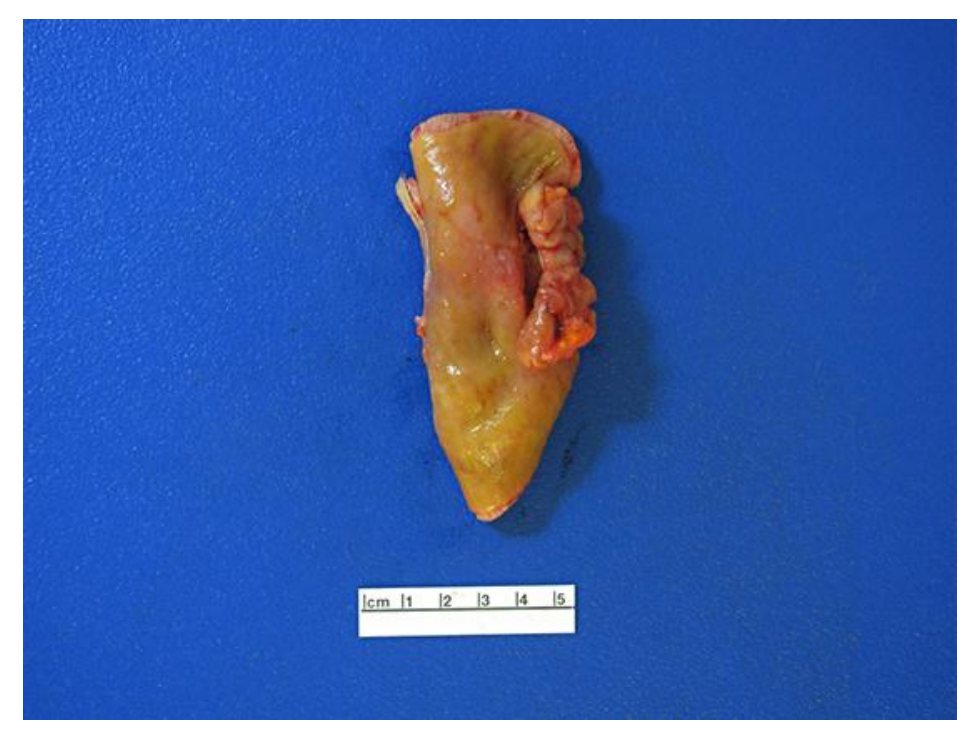

Fig. 2. Surgical resection identified the cause of the partial obstruction to be endometriosis.

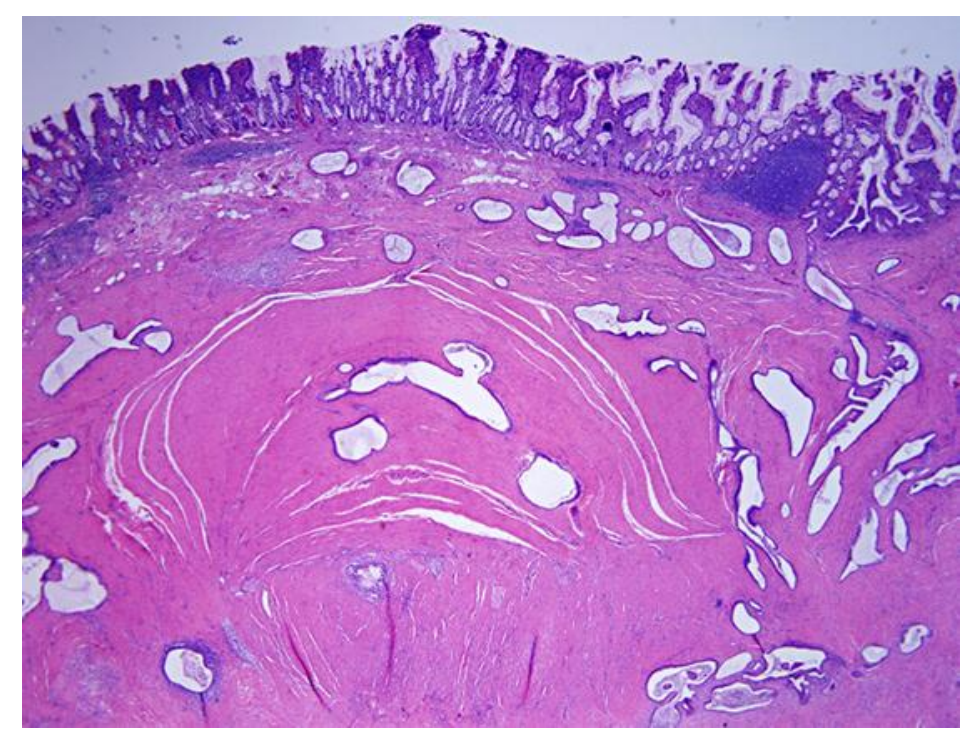

Fig. 3. Histology of the surgical specimen showed focal submucosal hemorrhage and serosal scarring. 